\title{
Living Situations and Social Support in the Era of Extended Foster Care: A View from the U.S.
}

\author{
Nathanael Okpych University of Connecticut, USA \\ nathanael.okpych@uconn.edu \\ Huiling Feng University of Chicago, USA \\ Keunhye Park University of Chicago, USA \\ Adrianna Torres-García University of Chicago, USA \\ Mark E. Courtney University of Chicago, USA
}

(Received February 2017 Revised November 2017)

http://dx.doi.org/10.14301/llcs.v9i1.449

\begin{abstract}
Social support is important for promoting resiliency and decreasing the occurrence and impact of negative life events as foster youth transition to adulthood. However, the types and amount of support may vary by where youth are placed. Additionally, it is not known whether state policies that extend the foster care age limit beyond age 18 are associated with greater social support. This paper examines how types and sources of social support vary by youths' foster care placement and foster care status at age 19. Data come from the CalYOUTH Study, a representative sample of youths in California foster care where 611 participants were interviewed at ages 17 and 19. Information was gathered on youths' perceived adequacy of three types of social support (emotional, tangible, and advice/guidance) and their sources of support (family, peers, and professionals). Overall, a third or more of the particpants reported having inadequate support in each of the three support domains, which calls for renewed efforts to ensure that foster youth have adults they can rely on as they transition to adulthood regardless of where they happen to be living. After controlling for prior social support and other characteristics, youth in foster homes with relatives had less contact with professionals than did youth in other placements. In-care youth were more likely than out-of-care youth to have adequate advice and tangible support and to identify a professional as a support. These findings provide early support for the role of extended care in linking youth to important social resources.
\end{abstract}

\section{Keywords}

Foster care youth; care leavers; extended foster care; foster care placement type; social support; transition to adulthood

\section{Introduction}

Past trauma, negative experiences in out-of-home placements, and the termination of care at age 18 in most countries leave foster youth a highly vulnerable group during the transition to adulthood. Family and peers can be important sources of support, but these relationships are often strained by histories of maltreatment and dislocation (Courtney, 2010; Courtney et al., 2005; Curry \& Abrams, 2015; Mendes, Johnson, \& Moslehuddin, 2012). Placement moves that foster youth commonly experience while in care can uproot existing ties to caregivers, schools, and communities (Stein, 2012; Van Breda, 2015; Wade, 2008). Unlike many youth who rely on their parents well into their $20 \mathrm{~s}$ for housing and other necessities, turning to parents for help may not be an option for some care leavers (Fowler, Toro, \& Miles, 2009; Toro, Dworsky, \& Fowler, 2007).
In the United States, the Fostering Connections to Success and Increasing Adoptions Act of 2008 (FCA) fundamentally changed foster care practice by giving states the option to extend the age limit of foster care from 18 to 21 (Courtney, 2009). The law is intended to promote positive transitions to adulthood by shielding youth from disruptive life events (e.g. homelessness) and providing opportunities and resources to build human and social capital. To date, more than 20 states have enacted laws that extend the foster care age limit past age 18 (National Conference of State Legislators, 2015). Implementing the new provisions of the law means that participating states are now responsible for supervising and providing care to young adults (non-minor dependents), which is very different from serving minors in care (Courtney, 2009). Changes will need to be made to existing service contexts and practices. For example, new housing 
options need to be made available that are developmentally appropriate for young adults.

While extended foster care is expected to benefit youth by meeting their basic needs (e.g. housing, daily living expenses) and enabling them to acquire education and training, it may also enhance youths' transition to adulthood by strengthening connections to individuals who can provide important resources and guidance. Social support is important because it can buffer youth from the occurrence and impact of negative life events, and it can enhance resiliency (Collins, Spencer, \& Ward, 2010; Stein, 2008; Van Breda \& Dickens, 2015). As foster youth prepare to leave state care, supportive individuals help make sense of the transition, assisting youth with clarifying their goals, mapping out their next steps, and making them feel understood and accepted (Collins et al., 2010). The presence of socially supportive individuals can be a source of constancy during a time of flux and uncertainty, and can build interdependence during a transition that is heavily focused on achieving independence (Curry \& Abrams, 2015; Samuels \& Pryce, 2008).

In U.S. states that have extended the foster care age limit, the amount and types of social support available to youth may be influenced by whether they remain in care past age 18 . Furthermore, among young adults participating in extended foster care, the sources and forms of available social support may depend, in part, on the type of living arrangement in which they reside. To address these important but largely unexplored issues, the present study draws on data collected in California, the state with the largest foster care population in the U.S. and one of the early adopters of the FCA (AFCARS, 2015; Courtney et al., 2016a; Webster et al., 2016). In this paper, we examine how the types and sources of social support vary by participation in extended foster care and by living arrangements among youth in extended care.

\section{Literature review}

\section{The role of social support during the transition to adulthood}

Despite the many cultural, systemic, and policy differences across nations, social support is generally recognised as playing a vital role for care leavers as they transition to adulthood (Atwool, 2016; Hiles, Moss, Wright, \& Dallos, 2013). Scholars have noted that many youth transitioning from foster care often remain disconnected from important social support figures (Courtney, 2010; Fowler, Toro \& Miles, 2011), while other care leavers experience difficulties in utilising available social supports (e.g. Samuels \& Pryce, 2008). Histories of trauma, loss, removal from one's family of origin, and frequent placement and school changes while in foster care may stifle or complicate the formation of trusting relationships with adults (Collins et al., 2010; Curry \& Abrams, 2015; Greeson et al., 2015; Samuels \& Pryce, 2008; Stein, 2012; Van Breda, 2015; Wade, 2008). However, several scholars have found that supportive networks of relatives, foster parents, mentors, workers, and peers that youth establish while in care are helpful during the process of leaving care, especially in terms of emotional or practical support (Dima \& Pinkerton, 2016; Mendes \& Snow, 2016; Stein, 2012). Additionally, youth who have a history of stable placement while in care, as well as a later and more gradual transition out of care, have been found to fare better in navigating the transition than youth with unstable placement histories and abrupt exits from care (Hiles et al., 2013). Some scholars in the U.S. draw attention to mixed messages that youth receive while in foster care. Strong emphasis is placed on both becoming self-sufficient and relying on others for support (Curry \& Abrams, 2015; Samuels \& Pryce, 2008). While independence can be a source of resilience, it can also lead to feelings of disconnection from others, cause anxiety about receiving emotional support, and prevent youth from forming relationships with potentially supportive individuals (Cunningham \& Diversi, 2012; Samuels \& Pryce, 2008).

Social support refers to actual and perceived help and aid provided by others (Curry \& Abrams, 2015). Researchers have found that care leavers actively seek out and create relationships that satisfy a need for belonging and trust, and they construct networks of individuals who can support and assist them in achieving their goals (Samuels, 2008; Van Breda, 2015). Two ways that social support has been differentiated is by type of support and source of support (Greeson, Garcia, Kim, Thompson, \& Courtney, 2015). Support type refers to the content of the support that is available or provided, and common types include emotional, informational, tangible, and companionship. Different types of social support provide distinct resources important for negotiating developmental transitions and challenges. For example, emotional support (e.g. caring, listening, showing empathy) can promote trust, esteem, and feelings of having reliable alliances with others (Greeson \& Bowen, 2008; Van Breda, 2015). Emotionally supportive relationships can lead youth to feeling understood and respected, maintain positive self-esteem in the face of hardships, and reduce feelings of loneliness and disconnection (Dima \& Pinkerton, 2016; Mendes \& Snow, 2016; Stein, 2012). Tangible support (e.g. financial resources, material goods, practical assistance) includes concrete resources and help that are instrumental in completing tasks, meeting material needs, and responding to emergencies (Greeson \& Bowen, 2008; Stein, 2012). Transitioning out of care often results in foster youth losing important resources and becoming increasingly responsible for their own material wellbeing (Courtney \& Heuring, 2005; Fowler, Toro, \& Miles, 2011; Masten, Obradovic, \& Burt., 2006). Informational support involves gathering and sharing important information. In addition to information needed for specific tasks (e.g. completing a job application), informational support includes advice about resolving conflicts, communicating effectively, and other interpersonal skills that help youth transition into adult roles and responsibilties (Dickens, 2016; Stein, 2012).

In terms of sources of support, connections to relatives, peers, professionals, and foster families have been found to be important for youth as they transition out of care (Wade, 2008; Stein, 2012). Studies report that the majority of foster youth stay in contact with relatives (Collins, Paris, \& Ward, 2008; Collins et al., 2010; Courtney, Dworsky, Cusick, Havlicek, Perez, \& Keller, 2007; Jones \& Kruk, 2005; Samuels \& Pryce, 2008). Findings are mixed with respect to the quality of transition-age foster youths' relationships with their relatives; studies generally find most young adults who aged out of care report a close relationship with at least one adult member of their birth family, although some care leavers report having ongoing conflicts with birth 
families (Cashmore \& Paxman, 2006; Courtney, 2010; Courtney, Piliavin, Grogan-Kaylor, \& Nesmith, 2001; Courtney et al., 2007; Curry \& Abrams, 2015; Mendes, Johnson, \& Moslehuddin, 2012; Samuels, 2008; Stein, 2012; Wade, 2008). For example, studies in Australia have found that young people express unresolved feelings of anger, rejection, and resentment in the wake of unsuccessful family reunifications (Mendes et al., 2012; Moslehuddin, 2010). In some cases, the process of returning to one's birth family disrupts positive relationships foster youth have formed while in care with other individuals such as friends, caregivers, and workers (Van Breda, 2015).

Friends, romantic partners, schoolmates, and other peers are another common source of support that care leavers rely on. Peers can provide advice and moral encouragement, serve as buffers from involvement in risky behaviour, and help foster youth during times of crisis such as unexpected bouts of homelessness (Garrett et al., 2008; Perez \& Romo, 2011; Toro, Dworsky, \& Fowler, 2007; Tyler \& Melander, 2011). Professionals are another potential source of support for care leavers. Youth in foster care come into contact with a wide range of professionals, including adults in child welfare services and courts, schools, mentoring programmes, and other arenas (Daining \& DePanfilis, 2007; Lemon, Hines, \& Merdinger, 2005; Stein, 2012). Some youth maintain contact with professionals in the child welfare system after leaving care, and these adults have been found to continue to serve supportive roles in the lives of care leavers (Collins et al., 2010; Dickens, 2016).

Types of support are often related to sources of support, as "certain types of support tend to come from specialised sectors of social networks" (Perry, 2006, p.386). Close, informal ties commonly serve a "bonding function," providing emotional support and companionship, while formal ties often serve a "bridging function," linking youth to resources and opportunities that may not be available in their emotionally-close networks (Lin, 2001). Studies of foster youth have found that informal networks of family and peers provide emotional support, tangible support, and companionship, while professionals commonly provide information and tangible support needed for task completion (Ferrand, Mounier, \& Degenne, 1999; Singer, Berzin, \& Hokanson, 2013; Wellman \& Wortley, 1989).

\section{Extended foster care in the U.S.}

The FCA represents a shift in U.S. child welfare policy toward greater acknowledgment and responsibility of the government in supporting older foster care youth as they transition to adulthood (Courtney, 2009). Key provisions of the FCA extend eligilbity for foster care services to age 21 , permit states to use foster care funds for housing costs for youth between ages 18 and 21 who had exited care after their 18th birthday, and extending public funding for health and mental health services up to age 21 for youth who remain in care ${ }^{1}$ (Fowler et al., 2011). To be eligible for extended care, youth must be in care on their 18th birthday and meet one of the following criteria: work 80 hours per month, participate in a program to remove barriers to employment, be enrolled in secondary or post-secondary school, or be unable to perform any of these activities due to a medical condition (Geen, 2009).

Upon the enactment of the California Fostering Connections to Success Act (Assembly Bill 12), California was one of the early adopters of the FCA (Courtney, Charles, Okpych, Napolitano, \& Halsted, 2014). Beginning in 2012, young people in California foster care have an option to remain in care until their 21st birthday. As the state with a substantial portion of the U.S. foster care population, California offers an important opportunity to investigate changes in youth outcomes in the post-FCA era (Courtney et al., 2014). Eastman and colleagues (2016) used state administrative data to investigate rates of extended foster care participation in California before and after the enactment of the law (Eastman, Putnam-Hornstein, Magruder, Mitchell, and Courtney, 2016). They found that, among youth who were in care at age 17 , the proportion of youth who were still in care at age 19 increased from 19\% in 2009 (pre-extended care era) to $67 \%$ in 2012 (extended care era). While the impact of extended foster care on youth outcomes remains to be seen, it is clear that the law increased the proportion of youth who remain in care beyond age 18.

\section{Living arrangements of foster youth in the U.S.}

The most common placement options for adolescents in foster care under age 18 include foster homes with non-relatives, foster homes with relatives, and congregate care placements (e.g. group homes, residential treatment centers) (Courtney, Terao, \& Bost, 2004; Eastman et al., 2016). In some cases, foster families are provided extra training and support from trained professionals to care for foster children with special behavioural, emotional, or physical needs.

For youth who remain in care after age 18, two additional placement options were created in California in recognition of youths' developmental needs and desire for more independence. Supervised Independent Living Placements (SILPs) allow youth to live on their own or with roommates in a placement approved by their caseworker (e.g. an apartment or college dorm) and they receive monthly payments to help pay for the cost of rent and living expenses. SILPs are the placements that provide youth in extended care with the most independence and autonomy. After youth reach age 18 , SILPs become a common living arrangement, with about one-third to one-half of non-minor dependents in California residing in these settings (Courtney et al., 2005; Courtney et al., 2016a; McCoy, McMillen, \& Spitznagel, 2008. The second new placement type is the Transitional Housing Placement (THP). For young people who may not be ready for the autonomy of SILPs, THPs are shared or scattered site apartments that provide foster youth with an array of psychoeducational, independent living skills, employment readiness, and other services to prepare them for adulthood. THPs are supervised and resource-intensive placements that are considerably more expensive than SILPs. While SILPs and THPs offer new living options to non-minor dependents, in practice, a major concern is the lack of safe, affordable housing for non-minor dependents, particularly in urban areas (Napolitano \& Courtney, 2014; Courtney et al., 2016b).

For youth who do not remain in foster care after age 18, residing with relatives or living on their own or with romantic partners are the most common living situations at age 19 (Courtney et al., 2005; Courtney et al., 2016a; McCoy et al., 2008). 


\section{Differences in social support by extended foster care participation and living arrangement in the} U.S.

Given the recency of extended foster care in the United States, little research has examined differences in the types and sources of social support between youth who remained in care beyond their 18th birthday and youth who exited care prior to reaching age 18. One study, which included two states where foster care ended at age 18 and one state where youth could remain in care to age 21 , did not find significant differences in the perceived availability of social support between in-care and out-of-care youth at age 19 (Courtney et al., 2005). Information on sources of support was not collected in this study. To our knowledge, no studies have investigated differences in type and source of social support among youth living in different extended foster care placements. Given the variety of living options available to nonminor dependents and that different placements may hinder or create opportunities for youth to access social support, this study addresses these gaps in knowledge with three analytic objectives:

1. Describe the living arrangements, types of social support, and sources of social support among foster youth, both at age 17 and at age 19.

2. Investigate whether types and sources of social support differ between youth who remained in care to age 19 and youth who had exited care.

3. Among youth who were still in foster care at age 19, investigate whether types and sources of social support differ by their living arrangements.

\section{Methods}

\section{Recruitment and sampling}

Data come from the California Youth Transitions to Adulthood Study (CalYOUTH), a longitudinal study of transition-age foster care youth in California (Courtney et al., 2014). The study was approved by the Institutional Review Board at the University of Chicago's School of Social Service Administration and the California Committee for the Protection of Human Subjects prior to initiating the study. The wave 1 interviews were conducted in 2013. Youths were eligible to participate in the study if they were between 16.75 and 17.75 years of age at the time of sample draw and had been in the California foster care system for at least six months. The sampling frame was created from data extracted from the California administrative data system for child welfare services. From the initial sampling frame of 2,583 youths, a stratified random sampling approach was used to divide California counties into six strata based on the total number of eligible youths in each county. After ineligible youths were excluded, the final sample for the wave 1 survey consisted of 763 youths. ${ }^{2}$ Of the 763 eligible youths, 727 completed the wave 1 interview, yielding a response rate of $95 \%$. Of the wave 1 respondents, two participants asked not to be contacted for follow-up interviews and one participant passed away between waves 1 and 2 . The remaining 724 youths were eligible to participate in the wave 2 interviews, which took place in 2015. A total of 611 youths completed wave 2 interviews, which is $81 \%$ of the study sample and $84 \%$ of the wave 1 respondents (Courtney et al., 2016a).

The sample for the present analysis includes youths who completed both the wave 1 and wave 2 interviews, which consists of 611 participants. We examined potential differences in all of the covariates measured at wave 1 , described below, between the 611 youths who completed both interview waves and the 116 youths who completed only the wave 1 interview. There were no statistically significant differences $(p<.05)$ between these two groups in any of the wave 1 measures.

\section{Data collection}

Wave 1 interviews occurred between April and October of 2013, and wave 2 interviews took place between March and December of 2015. Of the 611 wave 2 interviews, 592 were completed in person and 19 were completed by telephone, including five interviews with incarcerated participants. The wave 1 and wave 2 surveys each covered over 20 content areas and were designed to take 75 to 90 minutes to complete. Audioenhanced and computer-assisted self-interviewing was used for sensitive questions (e.g. sexuality, pregnancy, mental health, past maltreatment). As incentive to participate, youths were offered $\$ 50$ at the wave 1 interview and $\$ 60$ at the wave 2 interview.

Data collected from CalYOUTH Study interviews were linked to state child welfare administrative data, which were used to cross-check youths' self-reported foster care status and placement type at each of the two interview waves. Among the 611 respondents, 601 granted permission for CalYOUTH researchers to access administrative data for research purposes.

\section{Measures}

\section{Outcome measures: social support}

Three measures were used to capture social support types and three measures were used to capture sources of social support.

Types of Social Support. During both interview waves, participants were asked whether they had enough people to turn to for three types of social support. Emotional support pertains to having individuals to talk to about personal or private matters, or if youth had something on their mind that was worrying them or making them feel down. Tangible support pertains to having individuals to lend or give youth something they needed or pitch in to help them with something they needed to do (e.g. people who would run an errand for them; lend them money, food, or clothing; or drive them somewhere they needed to go). Informational support pertains to having individuals to turn to if youth needed advice or information (e.g. if youth did not know where to get something or how to do something they needed to do). The original response choices included "enough people you can count on," "some but not enough people you can count on," and "no one you can count on." For this analysis, binary variables were created for each support type, with one indicating they had enough support and zero indicating that they had no support or not enough support.

Sources of Social Support. The Social Support Network Questionnaire (SSNQ) was used to capture information on participants' sources of social support. The SSNQ is a brief instrument designed to measure aspects of youths' relationships with specific individuals who are nominated as people youth can 
turn to for different types of social support (Gee \& Rhodes, 2007). A modified version of SSNQ was administered during both waves to both meet interview time constraints and to tailor certain response options to a foster care population. ${ }^{3}$ During the study interview, participants were first asked to nominate up to three individuals they would most likely turn to for emotional support, up to three individuals they would most likely to turn to for tangible support, and up to three individuals the youths would most likely to turn to for informational support. Once a roster of nominated individuals was created, youths were asked follow-up questions about each nominee including their relationship with each person. For the present analysis, we classified nominees into three groups: professionals (caseworkers, teachers, school counsellors, therapists/counsellors, mentors, or some other professionals), relatives (siblings, biological parents, step-parents, aunts/uncles, cousins, and grandparents), and peers (friends, coworkers, classmates, and romantic partners). For each of these three groups, we created a count variable for the number of distinct individuals nominated by a respondent, as well as a binary variable with one indicating that the respondent nominated one or more individuals in this group and zero indicating that the respondent nominated zero individuals in this group. Similar to our measures of social support types, the measures of social support sources were collected at both wave 1 and wave 2 .

\section{Main grouping variables: Extended foster care status and foster care placement type}

Extended foster care status. Participants' extended foster care status was captured by a binary variable, with one indicating that the participant was in care at the time of the wave 2 interview and zero indicating that they were not in care.

Placement type. Participants who were in foster care were asked about their current living situation at both interview waves. For wave 1, the living arrangements included five categories: nonrelative foster home, relative foster home, therapeutic foster care agency home (TFC) ${ }^{4}$, congregate care (group home or residential treatment center), and other placement (guardian home, adoptive home, independent living arrangement, or courtspecified home). The wave 2 placement options included: nonrelative foster home, relative foster home, TFC home, supervised independent living placement (SILP), transitional housing placement (THP), and other placements (congregate care, guardian home, court specified home, jail/prison, and hospital/rehab) ${ }^{5}$.

\section{Control variables: Youth characteristics at age 17 (wave 1)}

Demographic characteristics. Information was gathered on participants' gender, race/ethnicity ${ }^{6}$ nativity status (born in the U.S. vs. not), and age at each interview wave. Recognising that sexual minority youth are often estranged from their families and sometimes experience marginalisation while in care (Wilson, Cooper, Kastanis, \& Nezhad, 2014), we also created a binary variable for youths' self-reported sexual minority status, with a one indicating that the participant identified with one of five statuses (mostly heterosexual, bisexual, mostly homosexual, $100 \%$ homosexual, or not sexually attracted to either males or females) and a zero indicating that they identified as $100 \%$ heterosexual.
Contact with biological parents. The strengths of youths' connections with their family of origin, particularly their birth parents, might influence their likelihood of obtaining support from both extended family members and from professionals connected to the foster care system. With this in mind, we controlled for youths' contact with each biological parent. At wave 1 , participants were asked about the number of visits they had with their birth mother and with their birth father in the past year. Binary variables were created for each biological parent indicating whether the youth had 12 or more visits with the parent in the past year (i.e. about one visit per month) or not.

Mental health status. Youths' mental health status could influence both their ability to seek social support and the likelihood that others would provide support. The Mini International Neuropsychiatric Interview for Children and Adolescents (MINI-KID) (Sheehan et al., 1998) was used to screen for the presence of various psychological disorders at wave 1 . The MINI-KID is a brief structured diagnostic tool used to assess DSMIV and ICD-10 psychiatric disorders in children and adolescents. Two binary variables were included in this analysis to capture the presence of depression (positive screen for Major Depressive Episode) and an externalising behaviour disorder [Conduct Disorder (CD) or Oppositional Defiant Disorder (ODD)].

\section{Analyses}

To address the first analytic objective identified earlier, we present descriptive statistics at age 17 and at age 19 on participants' social support, foster care status (age 19), and living arrangement. To address our second objective, to investigate whether social support varies by extended foster care status, we examine differences in types and sources of social support at age 19 between youth who were in care and youth who had exited care. Chi-square tests were used to test between-group differences for binary measures of social support, and analysis of variance (ANOVA) tests were used to examine between-group differences in the average number of individuals nominated for each social support source. Fischer's exact statistic and $p$-values are provided to indicate statistically significant $(p<.05)$ group differences. Since observed differences in social support between in-care and out-of-care youth could be due to other group differences, we also ran a series of regression analyses for each binary social support outcome measured at age 19 (wave 2) controlling for the following variables measured at age 17 (wave 1): youth demographic characteristics, social support ${ }^{7}$, placement type, parental contact during the past year, depression, and externalising behaviour problems. Logistic regression was used to examine differences in the log odds of the outcome by care status. Regression coefficients are presented as odds ratios for ease of interpretation, and abbreviated results from the regression analyses are reported, focusing on the relationship between care status and social support.

To address our third research objective of examining differences in social support at age 19 by foster care placement type, we limited our analyses to the youths who were still in care at wave $2(n=477)$ and used chi-square tests and ANOVA tests to examine overall differences in each social support measure by placement type. Additionally, binary logistic regression analyses were conducted to examine social support differences by placement type after controlling for wave 1 demographic 
characteristics, social support, placement type, and other control variables. Relative foster home was designated as the reference group, but other placement type differences were also explored and significant differences are reported in text.

Analyses were conducted using Stata version 14. All findings presented below apply survey weights, which take into account features of the sampling design and rates of non-response, and expand results to the population of California foster youth meeting the study criteria. Although missing data was infrequent for individual covariates, more than $5 \%$ of cases were missing values on at least one covariate included in the regression analyses. Multiple imputation by chained equations was used to address missing data in the regression analyses, and 25 imputed datasets were created and analysed (Royston \& White, 2011).

\section{Results}

\section{Sample characteristics}

Table 1 presents characteristics of the sample at wave 1 , when most youths were 17 years old. The sample was predominantly female, and nearly half of the youths identified themselves as Hispanic. About three-quarters of participants identified as $100 \%$ heterosexual, while the rest of the respondents characterised themselves as belonging to another sexual identity status. More than a quarter of respondents visited their birth mother at least on a monthly basis, and just one-tenth of participants were in monthly contact with their biological father. About one in five youths met the criteria for current depression, while about one-in-ten met the criteria for a behaviour problem (ODD or $C D$ ). Nearly all respondents reported that they were born in the U.S. In terms of foster care status, nearly all participants had not exited foster care by the time of their wave 1 interview. At the time of the follow-up interview when most youths were 19 years old, about three-quarters of participants were still in care.

\section{Description of living arrangments, types of social support, and sources of social support at ages 17 and 19}

Statistics on youths' living arrangements and social support at age 17 (wave 1) are presented in table 2. Among the young people who were still in care at wave 1 , the two placement types with a therapeutic component (TFC homes and congregate care) were the most common places youths were residing, making up about one-third and one-quarter of the placements respectively. Over one-third of participants lived in a foster home, either with a relative or a non-relative. Less than one-tenth of participants lived in an 'other placement', which included placement in an adoptive home $(n=6)$, with a legal guardian $(n=7)$, in an independent living arrangement $(n=23)$, or some other placements that youths specified $(n=9)$. When youths were asked about whether they had enough people to rely on for different types of support, advice/guidance was the type of support for which participants were most likely to report having adequate support, followed by emotional support and tangible support. Relatives and peers were the most common sources of support. One in three youths nominated a professional as someone they could turn to for support.

Table 1. Sample characteristics at age 17 ( $n=611$, weighted)

\begin{tabular}{|l|l|}
\hline Demographic Characteristics & \\
\hline Male (\%) & 40.0 \\
\hline Race/ethnicity (\%) & \\
\hline White & 17.4 \\
\hline Black & 17.4 \\
\hline Asian/Pacific Islander/American Indian/Alaskan Native & 2.3 \\
\hline Mixed race & 15.1 \\
\hline Hispanic & 47.6 \\
\hline Age at wave 1 interview (Mean/SD) & $17.5(0.3)$ \\
\hline Age at wave 2 interview (Mean/SD) & $19.5(0.3)$ \\
\hline Sexual minority status (\%) & 23.4 \\
\hline Birth mother visit at least once per month (\%) & 28.2 \\
\hline Birth father visit at least once per month (\%) & 10.2 \\
\hline Screened positive for major depression episode (\%) & 21.5 \\
\hline Screened positive for externalising disorder (\%) & 9.7 \\
\hline Born in the U.S. (\%) & 94.7 \\
\hline Care Status & \\
\hline In care at wave 1 (\%) & 95.7 \\
\hline In care at wave 2 (\%) & 77.3 \\
\hline
\end{tabular}


Table 2. Placement type and social support at age 17 ( $n=611$, weighted)

\begin{tabular}{|l|l|}
\hline Placement Type $^{\text {a } \%)}$ & \\
\hline Therapeutic Foster Care (TFC) home $^{\text {b }}$ & 32.6 \\
\hline Non-relative foster home & 16.8 \\
\hline Congregate care $^{\prime}$ & 23.8 \\
\hline Relative foster home & 20.3 \\
\hline Other placement & 6.6 \\
\hline${\text { Youths' Perceived Adequacy of Types of Social Support }{ }^{\text {(\%) }}}^{\text {Emotional support }}$ & \\
\hline Tangible support & 65.4 \\
\hline Advice/guidance & 58.5 \\
\hline Sources of Social Support (nominated individuals) & 72.3 \\
\hline Professionals & \\
\hline Nominated at least one (\%) & \\
\hline Number of nominated professionals (Mean/SD) & 32.0 \\
\hline Family supports & $0.5(0.8)$ \\
\hline Nominated at least one (\%) & \\
\hline Number of nominated family members (Mean/SD) & 73.9 \\
\hline Peer supports & $1.5(1.3)$ \\
\hline Nominated at least one (\%) & \\
\hline Number of nominated peers (Mean/SD) & 60.7 \\
\hline
\end{tabular}

a Includes only youths in care at wave 1 ( $n=587)$

b TFC is placement in a foster home with specifically trained foster parents for youths with mental or behavioural health needs. It is used as an alternative to congregage care.

c Adequate social support is operationally defined as a youth replying that they have "enough people to count on" for a given type of support, rather than having "too few people" or "no one to count on."

Information on youths' living arrangments and social support at age 19 (wave 2) is presented in table 3 . At the time of the wave 2 interview, about three-quarters of participants were in extended foster care. Among the youths in extended foster care, the greatest proportion of participants were living in a SILP. About one in five youths were living in a THP, and more than one in three youths were living in a foster home with a relative or nonrelative. Only $5 \%$ of participants were living in some 'other placement' type, such as a congregate care setting $(n=8)$, hospital or alcohol/substance use rehabilitation facility $(n=2)$, or some other living arrangement $(n=15)$. Overall, the proportions of youths who felt they had enough social support were lower at age 19 than at age 17 . However, the areas where youths felt most supported were similar across ages. Similar to age 17, the greatest proportion of youths at age 19 reported that they had enough people to turn to for advice, followed by emotional support and tangible support. In terms sources of support, family members continued to play a large role. Reliance on peers for support increased from age 17 to age 19 . Similar to the results at age 17 , professionals were a less common source of support for participants at age 19 . 
Table 3. Placement type and social support at age 19 ( $n=611$, weighted)

\begin{tabular}{|l|l|}
\hline Placement Type ${ }^{\text {(\%) }}$ & \\
\hline TFC home & 9.1 \\
\hline Non-relative foster home & 13.1 \\
\hline Relative foster home & 22.5 \\
\hline SILP & 31.4 \\
\hline THP-Plus & 19.2 \\
\hline Other & 4.8 \\
\hline Youths' Percieved Adequacy of Types of Social Support (\%) & \\
\hline Emotional support & 58.4 \\
\hline Tangible support & 53.3 \\
\hline Advice/guidance support & 65.1 \\
\hline Sources of Social Support (nominated individuals) & \\
\hline Professionals & \\
\hline Nominated at least one (\%) & 28.4 \\
\hline Number of nominated professionals (Mean/SD) & $0.4(0.7)$ \\
\hline Family supports & \\
\hline Nominated at least one (\%) & 69.8 \\
\hline Number of nominated family members (Mean/SD) & $1.2(1.1)$ \\
\hline Peer supports & \\
\hline Nominated at least one (\%) & 68.3 \\
\hline Number of nominated peers (Mean/SD) & $1.1(1.1)$ \\
\hline Includes only youths in care at wave 2 (n=477)
\end{tabular}

a Includes only youths in care at wave $2(n=477)$

The next table examines how types and sources of social support varied by living placement among participants who were in care at age 17. As displayed in table 4, differences were found in the proportions of youths who had enough emotional support and tangible support, as well as the proportions of youths who nominated family members and peers as supports. Regression analyses were run to identify where differences in social support existed between specific placement types. Notable differences were present for youths in congregate care settings and youths in kinship foster care, relative to other placement types. Youths in congregate care were less likely than youths in non-relative foster homes, relative foster homes, and 'other placements' to have enough emotional support. Youths in congregate care were also less likely than youths in non-relative foster homes, relative foster homes, and TFC homes to nominate a peer that they could turn to for support. Youth in relative foster homes were more likely than youth in TFC homes, non-relative foster homes, and congregate care to report having enough tangible support and, not surprisingly, to nominate family members as supports. 


\section{Table 4. Comparisons of social support by placement type at age 17 ( $n=611$, unweighted $n$, weighted $\%$ and mean/SD) ${ }^{a}$}

\begin{tabular}{|c|c|c|c|c|c|c|c|c|}
\hline & \multirow{2}{*}{$\begin{array}{l}\text { Overall } \\
(n=611)\end{array}$} & \multirow{2}{*}{$\begin{array}{l}\text { Youths in } \\
\text { Care a } \\
(n=587)\end{array}$} & \multicolumn{6}{|c|}{ Comparison by Placement Type among Youths in Care $(n=587)$} \\
\hline & & & $\begin{array}{l}\text { Non- } \\
\text { relative } \\
\text { foster } \\
\text { home } \\
(n=103)\end{array}$ & $\begin{array}{l}\text { Relative } \\
\text { foster } \\
\text { home } \\
(n=86)\end{array}$ & $\begin{array}{l}\text { TFC home } \\
(n=203)\end{array}$ & $\begin{array}{l}\text { Con- } \\
\text { gregate } \\
\text { care } \\
(n=128)\end{array}$ & $\begin{array}{l}\text { Other } \\
(n=67)\end{array}$ & $\mathrm{p}$ \\
\hline \multicolumn{9}{|l|}{ Youths' Perceived Adequacy of Types of Social Support (\%) } \\
\hline Emotional support & 65.4 & 64.7 & 71.9 & 75.6 & 63.0 & 52.5 & 64.8 & * \\
\hline Tangible support & 58.5 & 57.9 & 48.9 & 74.6 & 51.5 & 56.1 & 67.2 & ** \\
\hline Advice/guidance support & 72.3 & 71.9 & 69.8 & 83.7 & 71.7 & 65.3 & 66.2 & \\
\hline \multicolumn{9}{|l|}{ Sources of Social Support (nominated) } \\
\hline \multicolumn{9}{|l|}{ Professionals } \\
\hline Nominated at least one (\%) & 32.0 & 32.7 & 32.0 & 24.5 & 31.9 & 39.1 & 40.9 & \\
\hline Number of nominated professionals (Mean/SD) & $0.5(0.8)$ & $\begin{array}{l}0.5 \\
(0.8)\end{array}$ & $\begin{array}{l}0.5 \\
(0.9)\end{array}$ & $\begin{array}{l}0.4 \\
(0.7)\end{array}$ & $\begin{array}{l}0.4 \\
(0.7)\end{array}$ & $\begin{array}{l}0.6 \\
(1.0)\end{array}$ & $\begin{array}{l}0.6 \\
(1.0)\end{array}$ & \\
\hline \multicolumn{9}{|l|}{ Family supports } \\
\hline Nominated at least one (\%) & 73.9 & 73.5 & 68.9 & 87.8 & 68.5 & 70.8 & 75.4 & $* *$ \\
\hline \multicolumn{9}{|l|}{ Peer supports } \\
\hline Nominated at least one (\%) & 60.7 & 60.2 & 65.2 & 66.0 & 65.0 & 47.9 & 51.2 & * \\
\hline Number of nominated peers (Mean/SD) & $\begin{array}{l}1.0 \\
(1.1)\end{array}$ & $\begin{array}{l}1.0 \\
(1.1)\end{array}$ & $\begin{array}{l}1.0 \\
(1.1)\end{array}$ & $\begin{array}{l}1.0 \\
(1.0)\end{array}$ & $\begin{array}{l}1.1 \\
(1.2)\end{array}$ & $\begin{array}{l}0.8 \\
(1.0)\end{array}$ & $\begin{array}{l}0.9 \\
(1.2)\end{array}$ & \\
\hline
\end{tabular}

$* \mathrm{p}<.05, * * \mathrm{p}<.01, * * * \mathrm{p}<.001$

a Care status information at wave 1 was missing for three youths, and 21 youths had exited care between the time that the study sample was drawn based on child welfare administrative data and wave 1 interviews were conducted. These youths were therefore left out of these analyses. 


\section{Differences in types and sources of social support between youths who remained in care and youths who exited care}

Table 5 compares youths' adequacy and sources of social support by their care status at wave 2 (age 19). Compared to youth who had exited care, greater proportions of youths in care reported having enough people to turn to for tangible support and having enough people to turn to for advice/guidance. Additionally, in-care youths were more than four times as likely as youths who had left care to nominate at least one professional as a support. No significant differences were found between in-care youths and out-of-care youths for adequacy of emotional support and the likelihood of nominating peers and family as supports.

The differences observed in social support by care status at age 19 could be due to differences in youth characteristics. Table 6 presents abbreviated results of regression analyses that examined care status differences controlling for demographic characteristics, prior social support (age 17), placement type, and other background characteristics. Results indicate that after adjusting for these factors, differences by care status reported above remained statistically significant. The estimated odds of having enough people to turn to for tangible support were about $80 \%$ greater for youths in care versus youths who left care. A similar estimated odds ratio was found for advice/guidance. There was a particularly large difference in the likelihood of nominating at least one professional as a support; the estimated odds of nominating a professional for in-care youths were more than six times the estimated odds for out-of-care youths. Since caseworkers were included in the professional group, we were concerned that the care status differences may be driven largely by in-care youths nominating their caseworker. However, when we re-ran the analysis after removing nominated caseworkers, results were essentially unchanged (OR=6.58, p<.001). As suggested by previous research, we expected out-of-care youths to be more likely than youths still in care to nominate family members as sources of support. While the estimated odds ratio was in the expected direction, differences were not statistically significant.

Table 5. Comparisons of social support by care status at age 19 ( $n=611$, unweighted $n$, weighted $\%$ and mean/SD)

\begin{tabular}{|c|c|c|c|c|}
\hline & & $\begin{array}{l}\text { Out of } \\
\text { care } \\
(n=134)\end{array}$ & $\begin{array}{l}\text { In care } \\
(n=477)\end{array}$ & $\mathrm{p}$ \\
\hline \multicolumn{5}{|l|}{ Adequacy of Types of Social Support (\%) } \\
\hline Emotional support & 58.4 & 55.5 & 59.2 & \\
\hline Tangible support & 53.3 & 44.3 & 56.0 & * \\
\hline Advice/guidance support & 65.1 & 57.2 & 67.4 & * \\
\hline \multicolumn{5}{|l|}{ Sources of Social Support (nominated) } \\
\hline \multicolumn{5}{|l|}{ Professional } \\
\hline Nominated at least one (\%) & 28.4 & 7.9 & 34.4 & $* * *$ \\
\hline Number of nominated professional (Mean/SD) & $\begin{array}{l}0.4 \\
(0.7) \\
\end{array}$ & $\begin{array}{l}0.1 \\
(0.3) \\
\end{array}$ & $\begin{array}{l}0.5 \\
(0.8) \\
\end{array}$ & $* * *$ \\
\hline \multicolumn{5}{|l|}{ Family supports } \\
\hline Nominated at least one (\%) & 69.8 & 71.6 & 69.3 & \\
\hline Number of nominated family members (Mean/SD) & $\begin{array}{l}1.2 \\
(1.1)\end{array}$ & $\begin{array}{l}1.3 \\
(1.1)\end{array}$ & $\begin{array}{l}1.2 \\
(1.1)\end{array}$ & \\
\hline \multicolumn{5}{|l|}{ Peer supports } \\
\hline Nominated at least one (\%) & 68.3 & 66.0 & 68.9 & \\
\hline Number of nominated peers (Mean/SD) & $\begin{array}{l}1.1 \\
(1.1)\end{array}$ & $\begin{array}{l}1.2 \\
(1.2)\end{array}$ & $\begin{array}{l}1.1 \\
(1.1)\end{array}$ & \\
\hline
\end{tabular}

$* p<.05, * * * p<.001$ 
Table 6. Results from logistic regression analyses of wave $\mathbf{2}$ social support on care status at wave $\mathbf{2}$ ( $\mathrm{n}=\mathbf{6 1 1}$, covariates not shown, weighted)

\begin{tabular}{|c|c|c|c|c|c|c|c|c|c|c|c|c|}
\hline & \multicolumn{2}{|c|}{$\begin{array}{l}\text { Adequate } \\
\text { Emotional } \\
\text { Support }\end{array}$} & \multicolumn{2}{|c|}{$\begin{array}{l}\text { Adequate } \\
\text { Tangible Support }\end{array}$} & \multicolumn{2}{|c|}{$\begin{array}{l}\text { Adequate } \\
\text { Informational } \\
\text { Support }\end{array}$} & \multicolumn{2}{|c|}{$\begin{array}{l}\text { Nominated a } \\
\text { Professional }\end{array}$} & \multicolumn{2}{|c|}{$\begin{array}{l}\text { Nominated a } \\
\text { Relative }\end{array}$} & \multicolumn{2}{|c|}{$\begin{array}{l}\text { Nominated a } \\
\text { Peer }\end{array}$} \\
\hline & OR & $p$ & OR & $p$ & OR & $p$ & OR & $p$ & OR & $p$ & OR & $p$ \\
\hline (ref: Out of care) & & & & & & & & & & & & \\
\hline In care & 1.15 & .543 & 1.79 & .011 & 1.80 & .013 & 6.35 & $<.001$ & .86 & .551 & 1.04 & .884 \\
\hline
\end{tabular}




\section{Differences in types and sources of social support by placement type among youth who remained in care}

Table 7 presents differences in the social support types and sources of support by the living arrangments of young people who were still in care at age 19. No significant differences were found in adequacy of social support between youths living in different placements, although there were differences in all three sources of support. Youths living in non-relative foster homes relied heavily on peers as supports. These youths were significantly more likely to nominate peers as supports than were youths in all other placement types, except for youths in SILPs. Youths in SILPs had higher rates of peer support than did youths in some other placements (youths in TFC homes and relative foster homes). Perhaps unsurprisingly, participants residing in foster homes with relatives had particularly high rates of family support and were significantly more likely to nominate kin than were youths in non-relative foster homes and THPs. Participants living in relative foster homes were also less likely to nominate professionals than were youths in some other placement types (youth in TFC homes, SILPs, and THPs). A relatively high proportion of youths in THPs (which often have on-site staff) relied on professsionals for support compared to those in nonrelative foster homes.

Table 8 examines differences in social support by placement type among youths who were still in care at age 19, after controlling characteristics of the youth and their prior placement type, social support, and other background characteristics. Youths in relative foster homes were designated as the reference group in the results shown in table 8 . Similar to the descriptive statistics presented in table 7 , there were no differences between youths in different placements in perceptions of having enough emotional support, tangible support, and informational support. However, several placement differences remained in the types of people who were nominated as supports. Youths in relative foster homes were more likely than were youths in nearly every other placement type to nominate a family member and they were less likely than youths in SILPs, THPs, and TFC homes to nominate professionals. Youths living in relative foster homes were also less likely than were youths in SILPs and non-relative foster homes to nominate peers. Consistent with findings in table 7, participants in non-relative foster homes and SILPs were more likely than youths in some other placements to nominate peers. Youths living in non-relative foster care placements had significantly greater estimated odds than did youths residing in a TFC home, a relative foster home, or an 'other' placement of nominating a peer as a support. Youths in SILPs were more likely than were youths in a relative foster home and a TFC home to nominate a peer. Finally, youths in THPs and TFC homes were more likely than youths in non-relative foster homes, relative foster homes, and SILPs to nominate a professional as a support.

Although not displayed in tables 6 or 8, a key finding in all regression analyses was that a particular type or source of social support measured at age 17 was strongly predictive of that type or source of social support at age 19, net of the other covariates in the model ( $p<.001$ in nearly every regression analysis). For example, youths who reported having enough people to turn to for emotional support at age 17 were more likely than youths with inadequate emotional support at age 17 to report having enough emotional support at age 19 ( $O R=2.65, p<.001)$. As a second example, youths who nominated a professional at age 17 were more likely than youths who did not to later nominate a professional at age $19(\mathrm{OR}=2.19, \mathrm{p}<.001)$. These findings suggest that there is a robust relationship from age 17 to age 19 in social support. Having enough of a specific type of support at age 17 increased the likelihood that youths would report having enough of that support about two years later. Similarly, youths who nominated a specific source of support at age 17 had an increased likelihood of nominating the same source of support at age 19. 
Table 7. Comparisons of social support by placement type at age 19 among youth still in care ( $n=477$, unweighted $n$, weighted $\%$ and mean/SD)

\begin{tabular}{|c|c|c|c|c|c|c|c|}
\hline & $\begin{array}{l}\text { Non- } \\
\text { relative } \\
\text { foster } \\
\text { home } \\
(n=61)\end{array}$ & $\begin{array}{l}\text { Relative } \\
\text { foster } \\
\text { home } \\
(n=92)\end{array}$ & $\begin{array}{l}\text { SILP } \\
(n=142)\end{array}$ & $\begin{array}{l}\text { Trans- } \\
\text { itional } \\
\text { housing } \\
\text { place- } \\
\text { ment } \\
(n=114)\end{array}$ & $\begin{array}{l}\text { TFC home } \\
(n=43)\end{array}$ & $\begin{array}{l}\text { Other } \\
(\mathrm{n}=25)\end{array}$ & $p$ \\
\hline \multicolumn{8}{|l|}{ Adequacy of Types of Social Support (\%) } \\
\hline Emotional support & 54.1 & 58.1 & 60.8 & 57.4 & 73.3 & 48.6 & \\
\hline Tangible support & 52.7 & 65.8 & 57.6 & 44.4 & 58.9 & 48.8 & \\
\hline Advice/guidance support & 62.6 & 67.6 & 71.1 & 63.6 & 74.1 & 57.6 & \\
\hline \multicolumn{8}{|l|}{ Sources of Social Support (nominated) } \\
\hline \multicolumn{8}{|l|}{ Professional } \\
\hline Nominated at least one (\%) & 26.1 & 19.8 & 35.9 & 48.9 & 45.3 & 35.2 & $* *$ \\
\hline Number of nominated professional (Mean/SD) & $\begin{array}{l}0.3 \\
(0.6) \\
\end{array}$ & $\begin{array}{l}0.3 \\
(0.6) \\
\end{array}$ & $\begin{array}{l}0.5 \\
(0.7) \\
\end{array}$ & $\begin{array}{l}0.7 \\
(1.0) \\
\end{array}$ & $\begin{array}{l}0.7 \\
(0.9) \\
\end{array}$ & $\begin{array}{l}0.5 \\
(0.9) \\
\end{array}$ & $* *$ \\
\hline \multicolumn{8}{|l|}{ Family supports } \\
\hline Nominated at least one (\%) & 51.5 & 83.7 & 71.4 & 62.0 & 67.0 & 70.6 & $* *$ \\
\hline Number of nominated family members (Mean/SD) & $\begin{array}{l}0.8 \\
(1.0)\end{array}$ & $\begin{array}{l}1.8 \\
(1.1)\end{array}$ & $\begin{array}{l}1.1 \\
(0.9)\end{array}$ & $\begin{array}{l}0.9 \\
(1.0)\end{array}$ & $\begin{array}{l}1.1 \\
(1.0)\end{array}$ & $\begin{array}{l}1.3 \\
(1.1)\end{array}$ & $* * *$ \\
\hline \multicolumn{8}{|l|}{ Peer supports } \\
\hline Nominated at least one (\%) & 83.3 & 61.6 & 76.1 & 67.2 & 52.4 & 55.4 & $* *$ \\
\hline Number of nominated peers (Mean/SD) & $\begin{array}{l}1.3 \\
(1.0)\end{array}$ & $\begin{array}{l}1.0 \\
(0.9)\end{array}$ & $\begin{array}{l}1.3 \\
(1.1)\end{array}$ & $\begin{array}{l}1.1 \\
(1.2)\end{array}$ & $\begin{array}{l}0.7 \\
(0.8)\end{array}$ & $\begin{array}{l}0.9 \\
(1.0)\end{array}$ & $* *$ \\
\hline
\end{tabular}

$* * p<.01, * * * p<.001$

Table 8. Logistic regression analyses of wave 2 social support on foster care placement type at wave 2 ( $n=477$, covariates not shown, weighted)

\begin{tabular}{|c|c|c|c|c|c|c|c|c|c|c|c|c|}
\hline & \multicolumn{2}{|c|}{$\begin{array}{l}\text { Adequate } \\
\text { Emotional } \\
\text { Support }\end{array}$} & \multicolumn{2}{|c|}{$\begin{array}{l}\text { Adequate } \\
\text { Tangible Support }\end{array}$} & \multicolumn{2}{|c|}{$\begin{array}{l}\text { Adequate } \\
\text { Informational } \\
\text { Support }\end{array}$} & \multicolumn{2}{|c|}{$\begin{array}{l}\text { Nominated a } \\
\text { Professional }\end{array}$} & \multicolumn{2}{|c|}{$\begin{array}{l}\text { Nominated a } \\
\text { Relative }\end{array}$} & \multicolumn{2}{|c|}{ Nominated a Peer } \\
\hline & OR & $p$ & OR & $p$ & OR & $p$ & OR & $p$ & OR & $p$ & OR & $p$ \\
\hline \multicolumn{13}{|l|}{ (ref: Relative foster home) } \\
\hline Non-relative foster home & 0.91 & .803 & 1.20 & .641 & 1.57 & .275 & 2.01 & .110 & 0.24 & .001 & 2.83 & .019 \\
\hline SILP & 1.25 & .489 & 0.96 & .900 & 1.65 & .157 & 2.56 & .011 & 0.47 & .053 & 2.16 & .025 \\
\hline Transitional housing placement & 1.11 & .755 & 0.69 & .270 & 1.19 & .609 & 5.05 & $<.001$ & 0.29 & .001 & 1.31 & .413 \\
\hline TFC home & 2.65 & .061 & 1.06 & .905 & 1.33 & .579 & 7.47 & $<.001$ & 0.29 & .020 & 0.67 & .397 \\
\hline Other placement & 0.81 & .685 & 0.72 & .517 & 0.78 & .643 & 2.51 & .087 & 0.62 & .425 & 0.86 & .763 \\
\hline
\end{tabular}




\section{Limitations}

Several limitations of this study should be kept in mind when interpreting the findings. First, if the population of youth in care in California or the contexts of the transition to adulthood from care there differ from elsewhere, the findings may not apply to young people transitioning to adulthood from state care in other places. Second, while we did not find any statistically significant differences on observed characteristics between the youths who we were able to interview at both waves and the youths who only completed wave 1 , it is possible that these groups could differ in unmeasured characteristics that could bias study findings. Third, our social support measures may not have captured aspects of social support that are important to the transition to adulthood. Moreover, since we are not aware of the use of the social support measures with a representative population of young adults who were not involved with the child welfare system, we are not able to make comparisons with the overall young adult population. Lastly, while we have made efforts to control for characteristics of the study population that could confound our analyses of the relationship between extended care, placement type, and social support, the causal mechanisms underlying these relationships remain unclear.

\section{Discussion}

Although the primary focus of this study is on what sources and types of social support look like for young people who remain in foster care as adults, findings from our interviews with minors in care at age 17 are also instructive. As prior research has shown, many youth in foster care have ongoing contact with their family of origin; over one-quarter of our study subjects regularly saw one or both of their parents and nearly one-in-six lived with a relative while in care as a minor. Moreover, when asked to name the individuals whom they rely on for support, they named as many relatives on average as peers and professionals combined. Those in foster care with a relative at age 17 were more likely than their peers in therapeutic settings and nonrelative foster care to report adequate tangible support, which may speak to the relative willingness of kin to provide concrete support despite the fact that many of them have low incomes. A similar finding was reported at age 19, as young people in relative foster homes relied heavily on their family as people they turn to for support. Past research has reported that families can be an important source of tangible support (Dima \& Pinkerton, 2016; Mendes \& Snow, 2016; Stein, 2012). However, while most foster youth maintain contact with relatives (Collins et al., 2008; 2010; Courtney, et al, 2007; Jones \& Kruk, 2005; Samuels \& Pryce, 2008), relationships wth some family members, especially birth parents, can involve unresolved emotions and ongoing conflict (Collins et al., 2008; 2010; Courtney, 2010; Curry \& Abrams, 2015; Jones \& Kruk, 2005; Mendes et al., 2012; Samuels \& Pryce, 2008). We also found that youths residing with families may have less connection to professionals who can bridge them to information and resources that are useful in achieving their goals, such as pursuing higher education, finding a job, and accessing mental health services. While foster care agencies prioritise placements with relatives when possible, it may also be necessary for child welfare workers to redouble efforts to ensure that foster youth living with kin are connected to skilled, resourceful professionals such as teachers, school counsellors, religious figures, and advocates.

Youths in congregate care were less likely than those in family and family-like settings to report having adequate emotional support. Youth are typically placed in congregate care because they exhibit behavioural problems that make it difficult for them to live in family-like settings, behaviour that can undermine their ability to form supportive relationships. Group care settings also commonly employ shift-work staff, which may get in the way of youth in such settings forming long-term supportive relationships with the adults who care for them.

Supporting the findings of prior research on the topic (Courtney, 2010; Fowler et al., 2011; Samuels \& Pryce, 2008), the youths' perceived adequacy of support declined across all of the domains of social support we measured as they moved from being minors in state care to being young adults. For many of these young people, the autonomy associated with the transition to adulthood brings a sense of being on one's own without the support one had as a child. This provides some justification for the U.S. policy framework's focus on better supporting the transition to adulthood for foster youth.

Consistent with one of the primary justifications for extended foster care, our analyses suggest that allowing youth to remain in foster care into early adulthood connects them or allows them to remain connected with professionals who provide them with tangible support and guidance. Moreover, the placement types used to provide housing for youth perceived to need more adult care and supervision (TFCs and THPs) were most strongly associated with connections to professionals, suggesting that these living arrangements may be accomplishing one of their central purposes.

Placement type while in extended care was not associated with perceived adequacy of social support. Nevertheless, the fact that a third or more of the youths reported having inadequate support in each of the domains of support we studied calls for renewed efforts to ensure that these young people have adults they can rely on as they transition to adulthood, regardless of where they happen to be living. Policies and practices that promote the formation of natural mentors and peer mentors are promising initiatives. A natural mentor is, "a very important nonparental adult that exists in a youth's social network, like a teacher, extended family member, service provider, community member, or coach, who provides ongoing guidance, instruction, and encouragement aimed at developing the competence and character of the young person" (Thompson, Greeson \& Brunsink, 2016, p.48). Since natural mentors are selected from individuals with whom foster youth already have a connection, youth may be more 
receptive to efforts to strengthen existing relationships instead of beginning a relationship with a new adult. Interviews with foster youth have found that authenticity, trust, caring, shared interests, patience, and respect are important attributes of natural mentors (Greeson \& Bowen, 2008; Munson, Smalling, Spencer, Scott, \& Tracy, 2010), and effective mentors provide emotional support, guidance/advice, instrumental support, and parent-like support (Ahrens et al., 2011).

Peer mentoring is another promising initiative, which links foster youths with individuals who are older, who had also been in foster care, and who have positively transitioned to post-care life (Mezey et al., 2016; Middleton, 2012). Peer mentorship has the advantage of connecting foster youth to individuals with firsthand experience of being removed from their families, of being involved in foster care, and of having to transition to adulthood while losing support from state care. Peer mentors are also close in age and have an egalitarian dynamic that may not be present in relationships with professionals and other adults. Consequently, peer mentors can deliver information around personal matters that foster youth may be more willing to listen to than if communicated by an adult in a position of authority (Mezey et al., 2016). Training for natural mentors and peer mentors should include components of standard mentoring preparation (e.g. goal setting), but should also train mentors to anticipate and deal with relationship difficulties arising from trauma, living instability, and disrupted relationships experienced by foster youth.

The study findings also provide insight on extended foster care and social support. Importantly, extended care is not associated with a reduced likelihood that youth identify relatives as support, even though youth who remain in care are somewhat less likely than those who leave care to live with kin. This finding should help allay the fears of observers concerned that extended foster care may undermine youth's relationships with their families of origin. Extended care also had no relationship with the number of peers youth reported as sources of support, suggesting that remaining in care neither enhances nor hinders youth's relationships with peers.

While our study findings provide cautious support for the recently adopted U.S. policy of extended foster care, further research is needed to better inform how the policy can help youth acquire and maintain the support they need to succeed as adults. The nature of the relationship between extended care and support from professionals is one area needing investigation. Public agency caseworkers are present in the lives of these youth, but our analyses suggest that they do not account for all relationships between extended care and connections to professionals. Additionally, research should investigate different kinds of programmes and practices within the care system that can best strengthen young people's social support. In particular, while policies and practices that promote the formation of natural mentors and peer mentors are promising, rigorous evaluation research is needed to identify evidence-based approaches to supporting mentoring relationships for youth in foster care. Research also needs to gather youths' perspectives on their perceived relational needs and willingness to engage in different initiatives to increase their social capital (Munson et al., 2010). Future work is needed to examine the relationship between extended care and social support over a longer period of time than was observed in this study, including after foster youth reach the age of 21 and must leave care. Finally, the relationship between distinct forms of social support and other aspects of youth wellbeing during the transition to adulthood should be investigated, including research that assesses whether and how social support affects various outcomes.

\section{Disclaimer}

The findings reported herein were performed with the permission of the California Department of Social Services. The opinions and conclusions expressed herein are solely those of the author and should not be considered as representing the policy of the collaborating agency or an agency of the California government. 


\section{References}

AFCARS (2015). The AFCARS report: Preliminary FY 2014 estimates. Washington, DC: U.S. Department of Health and Human Services. Retrieved from http://www.acf.hhs.gov/programs/cb/resource/afcars-report-22

Ahrens, K. R., DuBois, D. L., Garrison, M., Spencer, R., Richardson, L. P., \& Lozano, P. (2011). Qualitative exploration of relationships with important non-parental adults in the lives of youth in foster care. Children and Youth Services Review, 33(6), 1012-1023. https://doi.org/10.1016/j.childyouth.2011.01.006

Atwool, N. (2016). Journeys of exclusion: Unpacking the experience of adolescent care leavers in New Zealand. In Young People Transitioning from Out-of-Home Care (pp. 309-328). P. Mendes \& P. Snow (Eds.). Palgrave Macmillan UK. https://doi.org/10.1057/978-1-137-55639-4 15

Cashmore, J. \& Paxman, M. (2006). Wards leaving care: Follow up five years on. Children Australia, 31(1), 18-25. https://doi.org/10.1017/S1035077200011196

Collins, M. E., Paris, R., \& Ward, R. L. (2008). The permanence of family ties: Implications for youth transitioning from foster care. American Journal of Orthopsychiatry, 78(1), 54-62. https://doi.org/10.1037/0002-9432.78.1.54

Collins, M. E., Spencer, R., \& Ward, R. (2010). Supporting youth in the transition from foster care: Formal and informal connections. Child Welfare, 89(1), 125.

Courtney, M. E. (2009). The difficult transition to adulthood for foster youth in the US: Implications for the state as corporate parent. Social Policy Report. Volume XXIII, Number I. Society for Research in Child Development.

Courtney, M. E. (2010). Social policy and the transition to adulthood in the U.S. In S. B. Kamerman, S. Phipps, A. Ben-Arieh (Eds.), From child welfare to child well-being (pp. 117-136). New York: Springer. https://doi.org/10.1007/978-90-481-3377-2 8

Courtney, M. E., Charles, P., Okpych, N. J., Napolitano, L., Halsted, K. (2014). Findings from the California Youth Transitions to Adulthood Study(CalYOUTH): Conditions of foster youth at age 17. Chicago, IL: Chapin Hall at the University of Chicago.

Courtney, M. E., Dworsky, A. L., Cusick, G. R., Havlicek, J., Perez, A., \& Keller, T. (2007). Midwest evaluation of the adult functioning of former foster youth: Outcomes at age 21. Chicago, IL: Chapin Hall Center for Children at the University of Chicago.

Courtney, M. E., Dworsky, A. L., Ruth, G., Keller, T., Havlicek, J., \& Bost, N. (2005). Midwest evaluation of the adult functioning of former foster youth: Outcomes at age 19. Chicago, IL: Chapin Hall Center for Children at the University of Chicago.

Courtney, M. E., \& Heuring, D. H. (2005). The transition to adulthood for youth "aging out" of the foster care system. In D. W. Osgood (Ed), On Your Own Without a Net: The Transition to Adulthood for Vulnerable Populations. (pp, 27-67). Chicago, IL: University of Chicago Press.

Courtney, M. E., Okpych, N. J., Charles, P., Mikell, D., Stevenson, B., Park, K., Kindle, B., Harty, J., \& Feng. H. (2016a). Findings from the California Youth Transitions to Adulthood Study (CalYOUTH): Conditions of youth at age 19. Chicago, IL: Chapin Hall Center for Children at the University of Chicago.

Courtney, M. E., Okpych, N. J., Mikell, D., Stevenson, B., Park, K., Harty, J., Feng, H., \& Kindle, B. (2016b). CalYOUTH Survey of young adults' child welfare workers. Chicago, IL: Chapin Hall Center for Children at the University of Chicago.

Courtney, M. E., Piliavin, I., Grogan-Kaylor, A., \& Nesmith, A. (2001). Foster youth transitions to adulthood: a longitudinal view of youth leaving care. Children and Youth Services Review, 80(6):685-717.

Courtney, M. E., Terao, S., \& Bost, N. (2004). Midwest evaluation of the adult functioning of former foster youth: Conditions of youth preparing to leave state care. Chicago, IL: Chapin Hall Center for Children at the University of Chicago.

Cunningham, M. J., \& Diversi, M. (2012). Aging out: Youths' perspectives on foster care and the transition to independence. Qualitative Social Work, 0, 1-16.

Curry, S. R., \& Abrams, L. S. (2015). Housing and social support for youth aging out of foster care: State of the research literature and directions for future inquiry. Child and Adolescent Social Work Journal, 32(2), 143-153. https://doi.org/10.1007/s10560-014-0346-4

Daining, C., \& DePanfilis, D. (2007). Resilience of youth in transition from out-of-home care to adulthood. Children and Youth Services Review, 29, 1158-1178. https://doi.org/10.1016/j.childyouth.2007.04.006

Dickens, L. (2016). The contribution of resilience to the 12-month transitional outcomes of care-leavers in South Africa. (Doctoral dissertation, University of Hohannesburg).

Dima, G., \& Pinkerton, J. (2016). The role of informal leaving care peer support networks in Romania. In P. Mendes \& P. Snow (Eds.), Young People Transitioning from Out-of-Home Care (pp. 409-426). Palgrave Macmillan UK. https://doi.org/10.1057/978-1-137-55639-4 20

Eastman, A. L., Putnam-Hornstein, E., Magruder, J., Mitchell, M. N., \& Courtney, M. E. (2016). Characteristics of youth remaining in foster care through age 19: A pre-and post-policy cohort analysis of California data. Journal of Public Child Welfare, 1-18.

Ferrand, A., Mounier, L., \& Degenne, A. (1999). The diversity of personal networks in France; social stratification and relational structures. Networks in the Global Village, 185-224. 
Fowler, P. J., Toro, P. A., \& Miles, B. W. (2009). Aging-out of foster care: Pathways to and from homelessness and associated psychosocial outcomes in young adulthood. American Journal of Public Health, 99, 1453-1458. https://doi.org/10.2105/AJPH.2008.142547

Fowler, P. J., Toro, P. A., \& Miles, B. W. (2011). Emerging adulthood and leaving foster care: Settings associated with mental health. American Journal of Community Psychology, 47(3-4), 335-348. https://doi.org/10.1007/s10464-010-9401-2

Garrett, S. B., Higa, D. H., Phares, M. M., Peterson, P. L., Wells, E. A., \& Baer, J. S. (2008). Homeless youths' perceptions of services and transitions to stable housing. Evaluation and program planning, 31(4), 436-444. https://doi.org/10.1016/i.evalprogplan.2008.04.012

Gee, C. B., \& Rhodes, J. E. (2007). A social support and social strain measure for minority adolescent mothers: A confirmatory factor analytic study. Child: Care, Health, and Development, 34(1), 87-97. https://doi.org/10.1111/j.1365-2214.2007.00754.x

Geen, R. (2009). The Fostering Connections to Success and Increasing Adoptions Act: Implementation issues and a look ahead at additional child welfare reforms. Working Paper. Child Trends. Retrieved from http://www.childtrends.org

Greeson, J. K., \& Bowen, N. K. (2008). "She holds my hand". The experiences of foster youth with their natural mentors. Children and Youth Services Review, 30(10), 1178-1188. https://doi.org/10.1016/j.childyouth.2008.03.003

Greeson, J. K. P., Garcia, A. R., Kim, M., Thompson, A. E., \& Courtney, M. E. (2015). Development \& maintenance of social support among aged out foster youth who received independent living services: Results from the multi-site evaluation of foster youth programs. Children and Youth Services Review, 53, 1-9. https://doi.org/10.1016/j.childyouth.2015.03.016

Hiles, D., Moss, D., Wright, J., \& Dallos, R. (2013). Young people's experience of social support during the process of leaving care: A review of the literature. Children and Youth Services Review, 35(12), 2059-2071. https://doi.org/10.1016/i.childyouth.2013.10.008

Jones, L., \& Kruk, E. (2005). Life in government care: The connection of youth to family. Child \& Youth Care Forum, 34, 405-421. https://doi.org/10.1007/s10566-005-7754-8

Lemon, K., Hines, A., \& Merdinger, J. (2005). From foster care to young adulthood: The role of independent living programs in supporting successful transitions. Children and Youth Services Review, 27, 251-270. https://doi.org/10.1016/j.childyouth.2004.09.005

Lin, N. (2001). Social capital: A theory of social structure and action. Port Chester, NY: Cambridge University Press. https://doi.org/10.1017/CBO9780511815447

Masten, A. S., Obradovic, J., \& Burt, K. B. (2006). Resilience in emerging adulthood: Developmental perspectives on continuity and transformation. In J. J. Arnett \& J. L. Tanner (Eds.), Emerging adults in America: Coming of age in the 21st century (pp. 173-190). Washington DC: American Psychological Association. https://doi.org/10.1037/11381-007

McCoy, H., McMillen, J. C., \& Spitznagel, E. L. (2008). Older youth leaving the foster care system: Who, what, when, where, and why? Children and Youth Services Review, 30(7), 735-745. https://doi.org/10.1016/i.childyouth.2007.12.003

Mendes, P., \& Snow, P. (2016). Young people transitioning from out-of-home care. Palgrave Macmillan. https://doi.org/10.1057/978-1-137-55639-4

Mendes, P., Johnson, G. and Moslehuddin, B. (2012). Young people transitioning from out-of-home care and relationships with family of origin: An examination of three recent Australian Studies. Child Care in Practice, 18(4), 357-370. https://doi.org/10.1080/13575279.2012.713849

Mezey, G., Robinson, F., Gillard, S., Mantovani, N., Meyer, D., White, S., \& Bonell, C. (2017). Tackling the problem of teenage pregnancy in looked-after children: a peer mentoring approach. Child \& Family Social Work, 22(1), 527-536. https://doi.org/10.1111/cfs.12225

Middleton, S. (2012). Peer mentoring opportunities for looked after children and care leavers. The Scottish Government, Edinburgh. Retrieved from http://www.scotland.gov.uk/Resource/0039/00394530

Moslehuddin, B. (2010). Graduating from the child welfare system: A critical examination of the needs of young people leaving state care. (Doctor of Philosophy Thesis, Monash University Department of Social Work, Melbourn).

Munson, M. R., Smalling, S. E., Spencer, R., Scott, L. D., \& Tracy, E. M. (2010). A steady presence in the midst of change: Non-kin natural mentors in the lives of older youth exiting foster care. Children and Youth Services Review, 32(4), 527-535. https://doi.org/10.1016/i.childyouth.2009.11.005

Napolitano, L., \& Courtney, M. E. (2014). Residential settings of young adults in extended foster care: A preliminary investigation. Chicago, IL: Chapin Hall Center for Children at the University of Chicago.

National Conference of State Legislators (2015). Extending foster care beyond 18. Retrieved from http://www.ncsl.org/research/human-services/extending-foster-care-to-18.aspx

Perez, B. F., \& Romo, H. D. (2011). "Couch surfing" of Latino foster care alumni: Reliance on peers as social capital. Journal of Adolescence, 34, 239-248. https://doi.org/10.1016/j.adolescence.2010.05.007

Perry, B. L. (2006). Understanding social network disruption: The case of youth in foster care. Social Problems, 53(3), 371-391. https://doi.org/10.1525/sp.2006.53.3.371 
Royston, P., \& White, I. R. (2011). Multiple imputation by chained equations (MICE): implementation in Stata. Journal of Statistical Software, 45(4), 1-20. https://doi.org/10.18637/jss.v045.i04

Samuels, G. M. (2008). A reason, a season, or a lifetime: Relational permanence among young adults with foster care backgrounds. Chicago, IL: Chapin Hall Center for Children at the University of Chicago.

Samuels, G. M., \& Pryce, J. M. (2008). "What doesn't kill you makes you stronger": Survivalist self-reliance as resilience and risk among young adults aging out of foster care. Children and Youth Services Review, 30(10), 1198--1210. https://doi.org/10.1016/j.childyouth.2008.03.005

Sheehan, D. V., Lecrubier, Y., Sheehan, K. H., Amorim, P., Janavs, J., Weiller, E., ... \& Dunbar, G. C. (1998). The Mini-International Neuropsychiatric Interview (MINI): The development and validation of a structured diagnostic psychiatric interview for DSM-IV and ICD-10. Journal of Clinical Psychiatry, 59, 22-33.

Singer, E. R., Berzin, S. C., \& Hokanson, K. (2013). Voices of former foster youth: Supportive relationships in the transition to adulthood. Children and Youth Services Review, 35(12), 2110-2117. https://doi.org/10.1016/i.childyouth.2013.10.019

Stein, M. (2008). Resilience and young people leaving care. Child Care in Practice, 14(1), 35-44. https://doi.org/10.1080/13575270701733682

Stein, M. (2012). Young People Leaving Care: Supporting pathways to adulthood. London : Jessica Kingsley.

Thompson, A. E., Greeson, J. K., \& Brunsink, A. M. (2016). Natural mentoring among older youth in and aging out of foster care: A systematic review. Children and Youth Services Review, 61, 40-50. https://doi.org/10.1016/j.childyouth.2015.12.006

Toro, P. A., Dworsky, A., \& Fowler, P. J. (2007). Homeless youth in the United States: Recent research findings and intervention approaches. The 2007 National Symposium on Homeless Research. Washington, DC: Office of the Assistant Secretary of Planning and Evaluation, U.S. Department of Health and Human Services and the Office Policy, Development, and Research, U.S. Department of Housing and Urban Development. Retrieved from https://www.huduser.gov/publications/pdf/homeless symp 07.pdf\#page=231

Tyler, K. A., \& Melander, L. A. (2011). A qualitative study of the formation and composition of social networks among homeless youth. Journal of Adolescence, 21(4), 802-817. https://doi.org/10.1111/j.1532-7795.2011.00739.x

Van Breda, A. D. (2015). Journey towards independent living: A grounded theory investigation of leaving the care of Girls \& Boys Town South Africa. Journal of Youth Studies, 18(3), 322-337. https://doi.org/10.1080/13676261.2014.963534

Van Breda, A. D. \& Dickens, L. (2015). Educational persistence and social exclusion among youth leaving residential care in South Africa. Nuances: Estudos sobre Educação, 25(1), 22-41.

Wade, J. (2008). The ties that bind: support from birth families and substitute families for young people leaving care. British Journal of Social Work, 38, 39-54. https://doi.org/10.1093/bjsw/bcl342

Webster, D., Armijo, M., Lee, S., Dawson, W., Magruder, J., Exel, M., Cuccaro-Alamin... \& Romero, R. (2016). CCWIP reports. Retrieved 4/11/2016, from University of California at Berkeley California Child Welfare Indicators Project website. URL: http://cssr.berkeley.edu/ucb childwelfare

Wellman, B. \& Wortley, S. (1989). Brothers' keepers: Situating kinship relations in broader networks of social support. Sociological Perspectives, 32(3), 273-306. https://doi.org/10.2307/1389119

Wilson, B. D., Cooper, K., Kastanis, A., \& Nezhad, S. (2014). Sexual and gender minority youth in foster care: Assessing disproportionality and disparities in Los Angeles. Los Angeles: The Williams Institute, UCLA School of Law. Retrieved from http://williamsinstitute.law.ucla.edu/?s=Sexual+and+gender+minority+y\&cat $=3$ 


\section{Endnotes}

1. Beginning in 2014, the Affordable Care Act extended the Medicaid age limit for qualifying foster care alumni to age 26 .

2. The initial sample included 880 youths. During the interview field period, 117 youths were excluded for one of the following reasons: physically or mentally unable to participate in an interview, on runaway status for at least two months, incarcerated during the field period, had returned home for at least two months, or had relocated out of state. See Courtney et al. (2014) for more information.

3. The original SSNQ gathered information on five types of social support and permitted youth to nominate an indefinite number of support individuals. Due to time constraints, we only asked about three types of social support and limited the number of nominees for each type to three individuals. In total, a respondent could nominate a maximum of nine distinct individuals. Additionally, when respondents were asked to identify their relationship to each nominated individual, several response options were added to reflect sources of support that foster youth commonly have access to (e.g. foster parent, caseworker, etc.). See Courtney et al. (2014) for more information.

4. TFC homes are licensed foster care homes that receive additional training and professional support to care for children with emotional, behavioural, and/or physical needs that require extra services. TFC homes are alternatives to congregate care placements.

5. Group home was collapsed into the 'other placement' category at wave 2 because fewer than 10 youths were in a congregate care setting at wave 2 .

6. Youths who reported that they were Hispanic were included in the Hispanic category and not the other race categories.

7. For example, when examining youths' adequacy of emotional support at wave 2, we controlled for youths' adequacy of social support at wave 1. 